\title{
Modelling Soil Moisture in Hyper-Arid Conditions
}

\author{
Yaping Shao ${ }^{1}$ (D) Klaus Fraedrich ${ }^{2} \cdot$ Masahide Ishizuka $^{3}$
}

Received: 26 August 2020 / Accepted: 5 December 2020 / Published online: 21 January 2021

(c) The Author(s) 2021

\begin{abstract}
In most land-surface models, the evolution of soil moisture is governed by soil-hydraulic processes. In hyper-arid soils, these processes break down, but soil moisture continues to show clear temporal variations, suggesting that other processes may be at work. We hypothesize that moisture in such soils varies due to evaporation in the soil and to vapour fluxes at the air-soil interface. To test this, we include vapour exchange between the air and soil in a landsurface model, apply the model to a desert site, and compare the simulated and observed soil moisture. The good agreement between the simulations and observations confirms our hypothesis. Using the model results, we examine the interactions between the soil-moisture and soil-vapour phases and influences of the soil-vapour phase on the surface energy balance.
\end{abstract}

Keywords Hyper-arid soils · Land-surface models · Soil moisture · Soil vapour · Surface energy balance

\section{Introduction}

Modelling soil moisture in arid regions is important because, in addition to its possible impact on the surface energy balance, desert microbiological and morphological processes may sensitively depend on soil moisture. For example, for aeolian-sand and dust-transport studies, the threshold friction velocity needs to be estimated, which depends critically on soil moisture (McKenna Neuman and Sanderson 2008). Improving the representation of soil moisture for arid regions in global climate models is important to better understand the physical processes underlying the long-term climate memory (Blender and Fraedrich 2006; Wang et al. 2010; Li and Wang 2020).

Soil moisture $\theta$ in hyper-arid regions is generally very low. In land-surface models (LSMs), the evolution of soil moisture is considered to be governed by soil-hydraulic processes. It is common that, for a given soil type, an air-dry soil moisture $\theta_{\mathrm{r}}$ is prespecified to define the smallest value of $\theta$ possible. For the Brooks and Corey (1964) soil-hydraulic parameters, $\theta_{\mathrm{r}}$

Yaping Shao

yshao@uni-koeln.de

1 Institute for Geophysics and Meteorology, University of Cologne, Cologne, Germany

2 Max Planck Institute for Meteorology, Hamburg, Germany

3 Faculty of Engineering and Design, Kagawa University, Kagawa, Japan 
$\approx 0.02 \mathrm{~m}^{3} \mathrm{~m}^{-3}$ (for sand), and for the van Genuchten (1980) soil-hydraulic parameters, $\theta_{\mathrm{r}}$ $\approx 0.045 \mathrm{~m}^{3} \mathrm{~m}^{-3}$. In some LSMs (e.g., Noah LSM, Chen and Dudhia 2001; Community Land Model, Oleson et al. 2013), $\theta_{\mathrm{r}}$ is not used, but soil-hydraulic fluxes and evapotranspiration are close to zero at some critical soil moisture. In Chen and Dudhia (2001), for example, this critical soil moisture appears to be the wilting soil moisture $\theta_{\mathrm{w}}$. The smallest value of $\theta_{\mathrm{w}}$ specified in the Noah LSM is $0.01 \mathrm{~m}^{3} \mathrm{~m}^{-3}$ for sand. Consequently, most LSMs do not effectively simulate soil moisture below a critical value, because in this situation the assumption that soil-hydraulic processes determine soil-moisture evolution breaks down.

However, the lowest soil moisture measured by Ishizuka et al. (2005a) in the Taklamakan Desert, China, in April 2002 using a time-domain reflectometer (TDR) was $\approx 0.005 \mathrm{~m}^{3} \mathrm{~m}^{-3}$; oven-dry samples are as low as $\theta \approx 0.001 \mathrm{~m}^{3} \mathrm{~m}^{-3}$, that is roughly an order of magnitude smaller than the lowest value of $\theta_{\mathrm{r}}$ specified in LSMs. The soil moisture observed in the Taklamakan Desert, although very low, underwent clear temporal variations (Fig. 3), which suggests that, in arid soils, processes other than those considered in LSMs are at work. We hypothesize that, in arid soils, $\theta \leq \theta_{\mathrm{r}}$ occurs due to internal soil evaporation and vapour fluxes at the air-soil interface. Conceptually, we divide the soil column into a saturated and an unsaturated zone, and the unsaturated zone into two subzones (Fig. 1). In subzone II, the evolution of the soil moisture $\theta$ is governed by Darcy flow, but in subzone I, by evaporation (and condensation) within the soil pores. To better model land-surface processes in arid regions, the exchange between the land surface and the atmosphere in the vapour phase should be considered.

We propose to include the exchange between air and soil in the vapour phase in landsurface modelling. The Atmosphere and Land Surface Interaction Scheme (ALSIS, Irannejad and Shao 1998; Shao and Irannejad 1999) is used as the basis for the model development. The revised ALSIS model, which is denoted as the ALSIS-D model, is tested using the observations reported by Ishizuka et al. (2005a). Based on model simulations, we examine the interactions between the soil-moisture and soil-vapour phases, and the influences of the soil-vapour phase on the surface energy balance.

Fig. 1 An unsaturated zone is divided into two subzones. In subzone II, soil moisture evolution is governed by Darcy flow. In subzone I, it is governed by evaporation and condensation in soil pores, and the soil moisture $\theta$ can be lower than the air-dry soil moisture $\theta_{\mathrm{r}}$

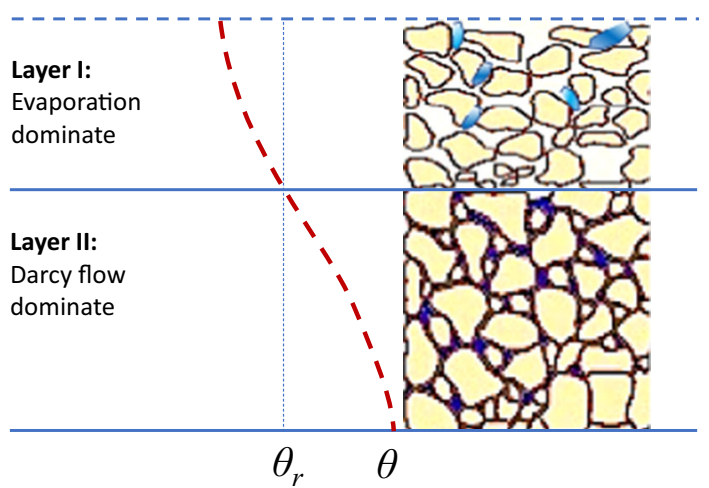




\section{Land-Surface Model Description}

\subsection{Hydrological Component}

The Richards equation is used for modelling soil moisture

$$
\partial \theta / \partial t=-\partial / \partial z[K(1-\partial \psi / \partial z)]+S,
$$

where $t$ is time, $z$ is the soil depth, $\psi$ is the soil water potential, $K$ is the hydraulic conductivity, and $S$ is a source term. The variables $K$ and $\psi$ depend nonlinearly on the soil moisture $\theta$, and thus solving (1) requires the functions $K(\theta)$ and $\psi(\theta)$ as closure. One of the commonly used closures is the Brooks-Corey closure (Brooks and Corey 1964)

$$
\begin{gathered}
\psi(\theta)=\psi_{\mathrm{s}} \Theta^{-b}, \\
K(\theta)=K_{\mathrm{s}} \Theta^{2 b+3},
\end{gathered}
$$

where $\psi_{\mathrm{s}}$ is the saturation soil water potential, $K_{\mathrm{S}}$ is the saturation hydraulic conductivity, $b$ is a parameter related to the pore-size distribution, and $\Theta$ is defined as

$$
\Theta=\frac{\theta-\theta_{\mathrm{r}}}{\theta_{\mathrm{s}}-\theta_{\mathrm{r}}},
$$

with $\theta_{\mathrm{s}}$ being the saturation soil moisture.

Clapp and Hornberger (1978) modified the Brooks-Corey closure by replacing the water retention function with a parabolic form for near saturation $\left(\psi_{i} \leq \psi \leq 0\right)$, where $\psi_{i}$ is the soil water potential at the inflection point. The near-saturation case is not of interest here, as our focus is on very dry situations. For $\psi<\psi_{i}$, the Clapp-Hornberger closure is formally the same as the Brooks-Corey closure, but with the value of $\theta_{\mathrm{r}}$ in (4) set to zero.

Equation 1 is solved subject to an upper boundary condition satisfying the surface water balance

$$
P_{\mathrm{r}}-I-E-R_{\mathrm{f}}=0,
$$

where $P_{\mathrm{r}}$ is the precipitation rate, $I$ is the infiltration rate, $E$ is the evaporation rate, and $R_{\mathrm{f}}$ is the surface runoff.

The evaporation rate is calculated using the bulk transfer formulation

$$
E=-\rho_{\mathrm{a}} \frac{q_{\mathrm{a}}-q_{0}}{r_{\mathrm{a}}},
$$

where $\rho_{\mathrm{a}}$ is the air density, $q_{\mathrm{a}}$ is the air specific humidity at reference level $z_{\mathrm{r}}, q_{0}$ is the air specific humidity at the moisture roughness length $z_{0 q}$, and $r_{\mathrm{a}}$ is the aerodynamic resistance for moisture flux from $z_{0 q}$ to $z_{\mathrm{r}}$. One way of estimating $q_{0}$ uses the $\beta$-method (Kondo et al. 1990),

$$
q_{0}=\beta q_{\mathrm{sat}}\left(T_{\mathrm{s}}\right)+(1-\beta) q_{\mathrm{a}},
$$

where $q_{\mathrm{sat}}\left(T_{\mathrm{s}}\right)$ is the saturation specific humidity at surface soil temperature $T_{\mathrm{s}}$, and $\beta$ is a coefficient related to surface moisture availability (Mahfouf and Noilhan 1991). The ALSIS model uses the $\beta$-method for computing evaporation using a $\beta$ parametrization modified from Lee and Pielke (1992)

$$
\beta=\left\{\begin{array}{ll}
0.125\left[1-\cos \left(\pi \theta / \theta_{f}\right)\right]^{3} & \theta>\theta_{f} \\
1 & \theta<\theta_{f}
\end{array},\right.
$$

where $\theta_{\mathrm{f}}$ is the field capacity $\left(\approx 0.75 \theta_{\mathrm{s}}\right)$. 


\subsection{Soil Temperature}

The exchange of heat in soil occurs through the mechanisms of conduction, the flow of liquid water, the diffusion of vapour, and convection. In the ALSIS model, as in other LSMs, the three latter processes are neglected, such that the soil temperature, $T$, satisfies

$$
\frac{\partial T}{\partial t}=\frac{\partial}{\partial z} D_{\mathrm{h}} \frac{\partial T}{\partial z}
$$

where $D_{\mathrm{h}}\left(=K_{\mathrm{h}} / C_{\mathrm{h}}\right)$ is the soil thermal diffusivity, $K_{\mathrm{h}}$ is the soil heat conductivity, and $C_{\mathrm{h}}$ is the soil volumetric heat capacity $\left(C_{\mathrm{h}}=\rho_{\mathrm{s}} c_{\mathrm{s}}, \rho_{\mathrm{s}}\right.$ and $c_{\mathrm{s}}$ are soil density and specific heat capacity, respectively). The quantities $\rho_{\mathrm{s}}, c_{\mathrm{s}}$, and $K_{\mathrm{h}}$ depend on the soil porosity and soil moisture. Neglecting the density and heat capacity of soil air, we obtain

$$
C_{\mathrm{h}}=\left(1-\theta_{\mathrm{s}}\right) \rho_{\mathrm{q}} c_{\mathrm{q}}+\theta \rho_{\mathrm{w}} c_{\mathrm{w}}
$$

and

$$
K_{\mathrm{h}}=419\left(a \theta+b \theta^{0.4}\right) \text {, }
$$

where $\rho_{\mathrm{q}}$ and $c_{\mathrm{q}}$ are the density and specific heat of quartz, respectively, and $\rho_{\mathrm{w}}$ and $c_{\mathrm{w}}$ are the density and specific heat of water, respectively. The constants $a$ and $b$ are soil-type dependent and are determined empirically for different soil types.

Surface soil temperature is calculated diagnostically by iteratively solving the surface energy balance equation

$$
R_{\mathrm{n}}\left(T_{\mathrm{s}}\right)-L E\left(T_{\mathrm{s}}\right)-H\left(T_{\mathrm{s}}\right)-G\left(T_{\mathrm{s}}\right)=0,
$$

where $R_{\mathrm{n}}$ is the net radiation, $H$ is the sensible heat flux, $G$ is the ground heat flux, and $L$ is the latent heat of vaporization.

Other model components of the ALSIS model (including surface radiation balance, calculation of canopy water storage, canopy evapotranspiration, canopy temperature, root distribution, aerodynamic resistance network, drag coefficients, surface runoff, infiltration, etc.) are as described in Irannejad and Shao (1998) and Shao and Irannejad (1999) and are not repeated here.

\subsection{Soil-Vapour Phase}

In the ALSIS model, soil-hydraulic and surface-hydrological processes govern the evolution of soil moisture and the lower limit of soil moisture is set to $\theta_{\mathrm{r}}$. At $\theta=\theta_{\mathrm{r}}$, as (2) and (3) show, the function $\psi$ is negative infinite and $K$ is zero, i.e., at this point the soil-hydraulic processes break down and no longer influence the evolution of soil moisture. In practice, $\theta_{\mathrm{r}}$ is an empirical constant. Even using the Clapp-Hornberger closure, for which $\theta_{\mathrm{r}}$ is set to zero, the soil-hydraulic fluxes are too small at low soil moisture to influence its change. In accordance with our hypothesis, we have revised the ALSIS model by including the soil-vapour phase, the revised scheme is referred to as the ALSIS-D model here.

For a given volumetric soil moisture $\theta$, the soil-air volume per unit soil volume is

$$
\Delta=\theta_{\mathrm{s}}-\theta,
$$


and the soil-air mass per unit soil volume is $\rho_{\mathrm{a}} \Delta$. We denote $C_{\mathrm{v}}$ as the soil-vapour mass concentration (soil-vapour mass per unit soil volume) and $C_{\mathrm{w}}\left(=\rho_{\mathrm{w}} \theta\right)$ as the soil-water mass concentration (soil-water mass per unit soil volume). For $\theta \geq \theta_{\mathrm{r}}$, we have

$$
\begin{gathered}
\frac{\partial C_{\mathrm{w}}}{\partial t}=\rho_{\mathrm{w}} \frac{\partial}{\partial z} K\left(1-\frac{\partial \psi}{\partial z}\right)-E_{\mathrm{w}}+\rho_{\mathrm{w}} S, \\
\frac{\partial C_{\mathrm{v}}}{\partial t}=-w \frac{\partial C_{\mathrm{v}}}{\partial z}+k_{\mathrm{p}} \frac{\partial^{2} C_{\mathrm{v}}}{\partial z^{2}}+E_{\mathrm{w}}, \\
\frac{\partial T}{\partial t}=\frac{\partial}{\partial z} D_{\mathrm{h}} \frac{\partial T}{\partial z}-L E_{\mathrm{w}},
\end{gathered}
$$

where $E_{\mathrm{w}}\left(\mathrm{kg} \mathrm{m}^{-3} \mathrm{~s}^{-1}\right)$ is the evaporation rate per unit soil volume and $k_{\mathrm{p}}$ is the mean soil-vapour diffusivity, which we set to the molecular diffusivity $\kappa_{\mathrm{p}}\left(\mathrm{m}^{2} \mathrm{~s}^{-1}\right)$. Considering that $k_{\mathrm{p}}$ depends on the soil-pore structure and varies with depth, and an air-pressure gradient exists which drives systematic motion, we include an advection term, $w \partial C_{\mathrm{v}} / \partial z$, in Eq. 14, with $w$ being an advective velocity. The inclusion of the advection term is demonstrated to be necessary in Sect. 5. For $\theta<\theta_{\mathrm{r}}$, Eq. 13 is simplified to

$$
\frac{\partial C_{\mathrm{w}}}{\partial t}=-E_{\mathrm{w}} \text {. }
$$

Consider now the evaporation rate per unit soil volume $E_{\mathrm{w}}$. The evaporation rate per unit area of soil-water surface, $e_{\mathrm{p}}\left(\mathrm{kg} \mathrm{m}^{-2} \mathrm{~s}^{-1}\right)$, can be expressed as

$$
e_{\mathrm{p}}=-g_{\mathrm{p}} \rho_{\mathrm{a}}\left(q_{\mathrm{p}}-q_{\mathrm{sat}}(T)\right),
$$

where $q_{\mathrm{p}}=C_{\mathrm{v}} /\left(\rho_{\mathrm{a}} \Delta\right)\left(\mathrm{kg} \mathrm{kg}^{-1}\right)$ is the soil-air specific humidity and $q_{\mathrm{sat}}(T)$ is the specific humidity at the soil temperature $T$. A conductance $g_{\mathrm{p}}\left(\mathrm{m} \mathrm{s}^{-1}\right)$ is related to the molecular diffusivity $\kappa_{\mathrm{p}}\left(\mathrm{m}^{2} \mathrm{~s}^{-1}\right)$ via $g_{\mathrm{p}}=\kappa_{\mathrm{p}} / l$, with $l$ being a length scale (of order of the pore size). Equation 17 can also be written as

$$
e_{\mathrm{p}}=-\frac{\kappa_{p}}{l \Delta}\left(C_{\mathrm{v}}-C_{\mathrm{vs}}\right)
$$

with $C_{\mathrm{vs}}=\rho_{\mathrm{a}} q_{\mathrm{sat}}(T), \Delta$ being the soil-vapour mass concentration at soil-vapour saturation. Suppose the soil water per unit soil volume has a surface area $A\left(\mathrm{~m}^{2} \mathrm{~m}^{-3}\right)$ exposed to soil air, then

$$
E_{w}=-\frac{\kappa_{\mathrm{p}}}{l \Delta} A\left(C_{\mathrm{v}}-C_{\mathrm{vs}}\right)
$$

with assumptions required concerning the properties of $A$ and $l$. It is advantageous to assume that

$$
A=a \sqrt{\theta \Delta} / l,
$$

such that $A=0$ for $\theta=0$ or $\Delta=0$, where $a$ is a dimensionless coefficient of $O(1)$. This reduces (19) by one parameter and leads to

$$
E_{w}=\gamma \sqrt{\frac{\theta}{l \Delta}}\left(C_{\mathrm{v}}-C_{\mathrm{vs}}\right)
$$

with the parameter $\gamma=-a \kappa_{\mathrm{p}} / l^{2}$ to be specified. Note that $O\left(\kappa_{\mathrm{p}}\right)$ is $10^{-6} \mathrm{~m}^{2} \mathrm{~s}^{-1}$ and $O(l)$ is $10^{-3} \mathrm{~m}$, such that $O(\gamma)$ is $O(1) \mathrm{s}^{-1}$.

More complicated considerations of the length scale $l$ can be made. For example, suppose the pore size is $s$, with maximum $s_{\max }$, and the normalized pore size is $s^{\prime}=s / s_{\max }$. If we assume that larger soil pores dry out first, we then have

$$
\theta=\theta_{\mathrm{s}} P\left(s^{\prime}\right),
$$


with $P\left(s^{\prime}\right)=\int_{0}^{s^{\prime}} p(x) \mathrm{d} x$ and $p(x)$ being the pore-size probability density function. It is reasonable to set

$$
l=s^{\prime} s_{\max }=s_{\max } P^{-1}\left(\theta / \theta_{\mathrm{s}}\right),
$$

where $P^{-1}$ is the inverse function of $P$.

At the air-land interface, in addition to evaporation (soil water to air vapour), a vapour flux (soil vapour to air vapour) needs to be included, which serves as the upper boundary condition for (14). This flux $F_{\mathrm{cv}}$ is given by

$$
F_{\mathrm{cv}}=-g_{\mathrm{pa}} \rho_{\mathrm{a}} \Delta_{1}\left(q_{\mathrm{p} 1}-q_{0}\right),
$$

where $\Delta_{1}$ and $q_{\mathrm{p} 1}$ are, respectively, $\Delta$ and soil-air specific humidity in the first soil layer. The factor $\Delta_{1}$ is included as it is the volume of the soil air responsible for the vapour flux. The molecular conductance $g_{\mathrm{pa}}$ is similar to $g_{\mathrm{p}}$, but is computed as

$$
g_{\mathrm{pa}}=\left(\frac{l}{\kappa_{\mathrm{p}}} g_{\mathrm{a}}\right)^{1 / 2},
$$

where $g_{\mathrm{a}}$ is aerodynamic conductance as for evaporation.

\section{Qira Field Experiment}

The Qira data are used to drive the ALSIS-D model and compare with the ALSIS-D simulations. The Qira experiment was carried out at a Gobi site $\left(36^{\circ} 54^{\prime} 07^{\prime \prime} \mathrm{N}, 80^{\circ} 47^{\prime} 07^{\prime \prime} \mathrm{E}\right)$ near the Qira Oasis south of the Taklimakan Desert in April 2002 by Mikami et al. (2002). The data collected during ADEC-IOP1 [the Asian Dust Experiment - Intensive Observation Period 1 in the period 1007 UTC 7 April-1041 UTC 18 April 2002 (97-108 Julian Day)] are used here (Ishizuka et al. 2005a). The site, located $13.7 \mathrm{~km}$ to the west of Qira and $1400 \mathrm{~m}$ above sea level, is characteristically Gobi and has no vegetation.

Soil samples were collected at the site during the period of 28 March to 15 April 2002. They were taken at nine locations in an area of $20 \times 20 \mathrm{~m}^{2}$ at $0.01-\mathrm{m}$ and $0.05-\mathrm{m}$ depths with a $50-\mathrm{mL}$ soil cup. The samples were dried in an oven at $105{ }^{\circ} \mathrm{C}$ for $24 \mathrm{~h}$ for soilmoisture measurements. The oven-dried mass was measured using an electric balance with an accuracy of $10^{-7} \mathrm{~kg}$ (BP211D, Sartrius, Göttingen, Germany). The oven-dried soil-moisture measurements were then used to calibrate the TDR sensors deployed at the field site for measuring soil moisture.

Atmospheric variables, including wind speed, wind direction, air temperature, and air humidity, were monitored using an automatic weather station, with data recorded using a data logger (CR10X, Campbell Scientific, Utah, USA) at intervals of $1 \mathrm{~min}$. The wind speed $U$ was measured at $0.45,1.38$, and $3.8 \mathrm{~m}$ above ground level, and the wind direction at $3.8 \mathrm{~m}$. In addition to soil moisture, soil temperature, soil heat fluxes, and radiation fluxes, including upwards and downwards shortwave and longwave radiation, were measured.

The forcing data used to drive the ALSIS-D scheme are shown in Fig. 2, including SolDn (solar radiation in $\mathrm{W} \mathrm{m}^{-2}$ ), $L w D n$ (longwave radiation in $\mathrm{W} \mathrm{m}^{-2}$ ), $T_{\text {air }}$ (air temperature in $\mathrm{K}$ ), and $q_{\text {air }}$ (specific humidity in $\mathrm{kg} \mathrm{kg}^{-1}$ ). As surface pressure was not measured, it is set to $870 \mathrm{hPa}$ for the entire study period according to Mikami et al. (2005). It is seen that the air temperature was generally between 280 and $302 \mathrm{~K}$, and specific humidity between 0.002 and $0.01 \mathrm{~kg} \mathrm{~kg}^{-1}$, but mostly below $0.004 \mathrm{~kg} \mathrm{~kg}^{-1}$. During the period, no rainfall was recorded. 


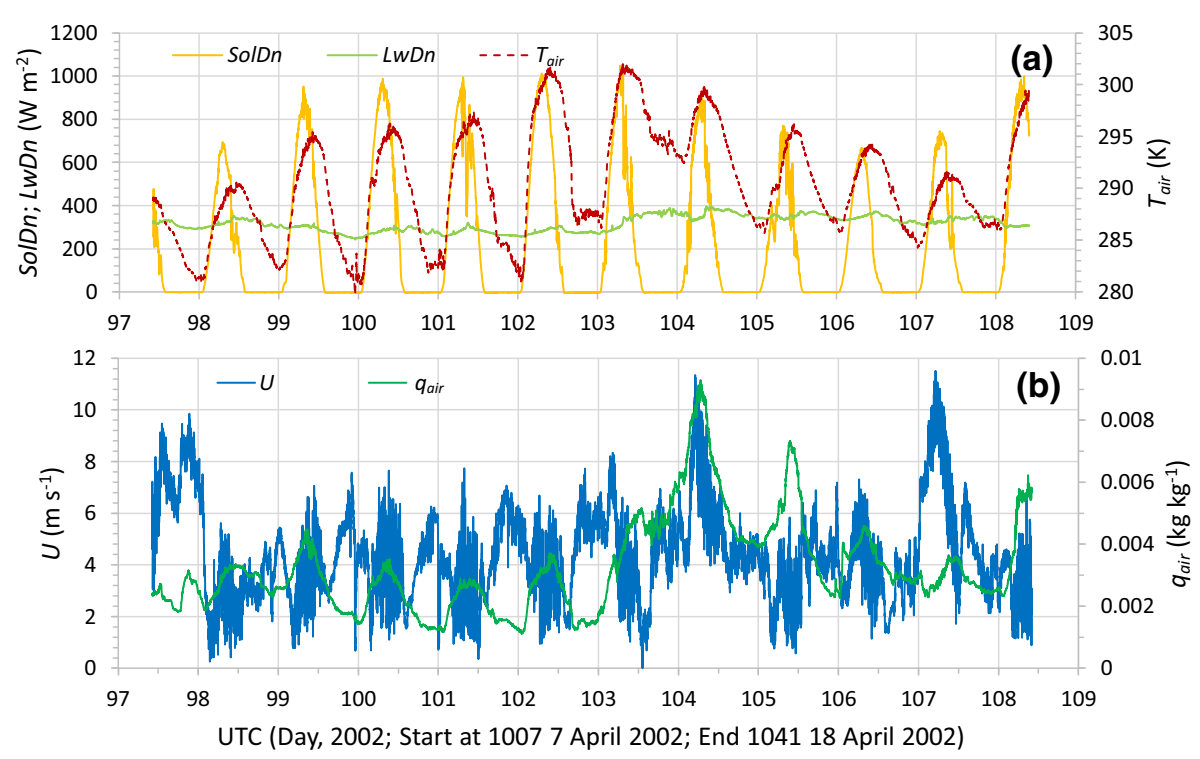

Fig. 2 Atmospheric forcing data from the Qira experiment for driving the ALSIS-D model. a Time series of SolDn (shortwave flux, $\mathrm{W} \mathrm{m}^{-2}$ ), $L w D n$ (longwave flux, $\mathrm{W} \mathrm{m}^{-2}$ ) and $T_{\text {air }}$ (air temperature, $\mathrm{K}$ ); $\mathbf{b}$ As (a), but for $U$ (wind speed, $\mathrm{m} \mathrm{s}^{-1}$ ), and $q_{\text {air }}$ (specific humidity, $\mathrm{kg} \mathrm{kg}^{-1}$ ). During the period, there was no rainfall. Surface pressure is set to a constant of $870 \mathrm{hPa}$

Soil moisture was measured using TDR sensors (CS615, Campbell Scientific, Utah, USA). The applicability of the TDR instrument in a hyper-arid environment was tested in a laboratory (Ishizuka and Mikami, 2005). The sensors were set horizontally at a depth of $0.01 \mathrm{~m}$ at nine points in the $20 \times 20 \mathrm{~m}^{2}$ sampling area. At the centre of the area, three TDR sensors were set at the depths of $0.01,0.05$, and $0.40 \mathrm{~m}$, and at the other eight locations at the $0.05-\mathrm{m}$ depth. Figure $3 \mathrm{a}$ shows the soil-moisture measurements for the depths 0.01 and $0.05 \mathrm{~m}$. Three observations can be made: (1) at the site, the value of $\theta$ could be very low, especially at $0.01-\mathrm{m}$ depth, becoming as low as $0.0054 \mathrm{~m}^{3} \mathrm{~m}^{-3}$; (2) even at such low values, the soil moisture $\theta$ underwent clear diurnal variations with an amplitude of about $0.001 \mathrm{~m}^{3} \mathrm{~m}^{-3}$; and (3) over the study period, a downwards trend can be detected, indicating an overall drying trend. Figure $3 b$ shows the soil-moisture measurements at a depth of $0.4 \mathrm{~m}$, where the soil moisture was roughly constant at $0.01 \mathrm{~m}^{3} \mathrm{~m}^{-3}$, but slightly increasing.

The Qira observations have been quality checked and used for other purposes in previous studies (Ishizuka and Mikami 2005; Ishizuka et al. 2005a, b; Shao and Mikami 2005). The dataset is again used here, because it is a rare and homogenized dataset suitable for testing soil-moisture modelling in a hyper-arid environment.

\section{Results}

The analysis of the model results focuses on (1) the exchange between the soil-moisture and soil-vapour phases; and on (2) the comparison of land-surface processes with and without the soil-vapour phase. 


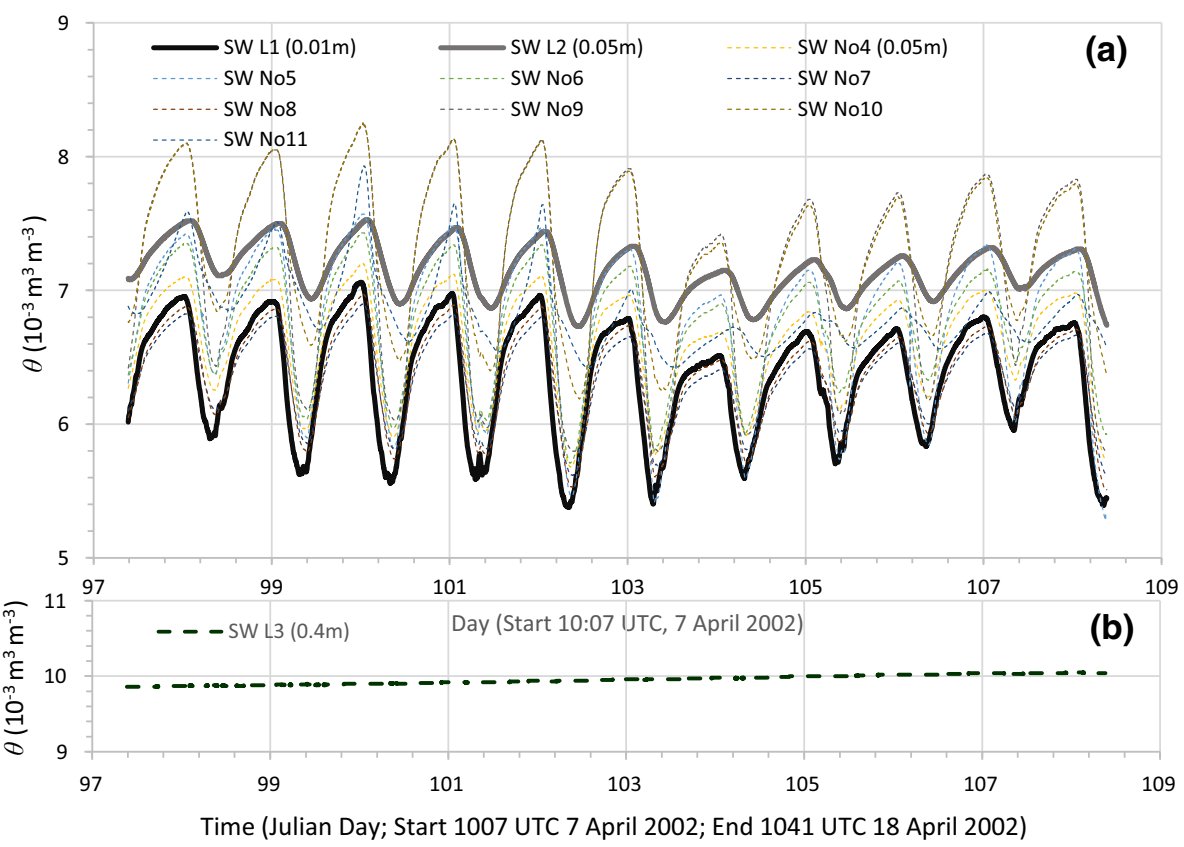

Fig. 3 Volumetric soil moisture $\theta\left(\mathrm{m}^{3} \mathrm{~m}^{-3}\right)$ measured using a TDR sensor at the Qira site: $\mathbf{a} \theta$ at $0.01-\mathrm{m}$ depth $(\mathrm{SW} \mathrm{L1} 0.01 \mathrm{~m})$ and $0.05-\mathrm{m}$ depth (SW L1 $0.05 \mathrm{~m}$ ) at the centre location, and at $0.05-\mathrm{m}$ depth at the other eight locations (SW No4, SW No5, etc.); b $\theta$ at 0.4-m depth (SW L3 $0.4 \mathrm{~m}$ ) at the centre location

\subsection{Results with the Soil-Vapour Phase}

For the simulations, the Clapp-Hornberger closure is used for its advantage of having one parameter less than the other similar closures. A soil layer of $1.21 \mathrm{~m}$ is divided into eight sublayers with thicknesses of $0.01,0.02,0.03,0.05,0.1,0.2,0.3$, and $0.5 \mathrm{~m}$, from top to bottom. The atmospheric forcing data are repeatedly used to drive the ALSIS-D model. The initial conditions of soil moisture and soil temperature are first estimated from the field measurements but then, after each repetition, set to the corresponding averages over the simulation time. The repetition is performed 10 times to allow these averages to become steady. The soil layer is divided into two horizons. The first horizon is sand, $0.51 \mathrm{~m}$ thick, consisting of the top six sublayers, and the second horizon is loamy sand, $0.7 \mathrm{~m}$ thick, consisting of the last two sublayers. The Clapp-Hornberger hydraulic parameters are set according to the tests reported in Shao and Irannejad (1999), with minor adjustments to obtain improved agreement with the measurements.

Due to the inclusion of soil vapour, we have introduced in (14) the soil vapour diffusivity $\kappa_{\mathrm{p}}$ and an advective velocity $w$ and in (21) the $\gamma$ parameter. A control experiment and a number of sensitivity experiments are performed, and the parametric values used for these experiments are listed in Table 1.

The Qira measurements show that soil moisture at $0.01 \mathrm{~m}$ and $0.05 \mathrm{~m}$ varied around $6 \times$ $10^{-3}$ and $7 \times 10^{-3} \mathrm{~m}^{3} \mathrm{~m}^{-3}$, with a variation range of around $\pm 1 \times 10^{-3}$ and $0.5 \times 10^{-3} \mathrm{~m}^{3}$ $\mathrm{m}^{-3}$, respectively. Several parameters influence the model outcomes, and a quantitatively satisfactory simulation with respect to the field observations is achieved only after numerous trial and error experiments by varying model parameters. 


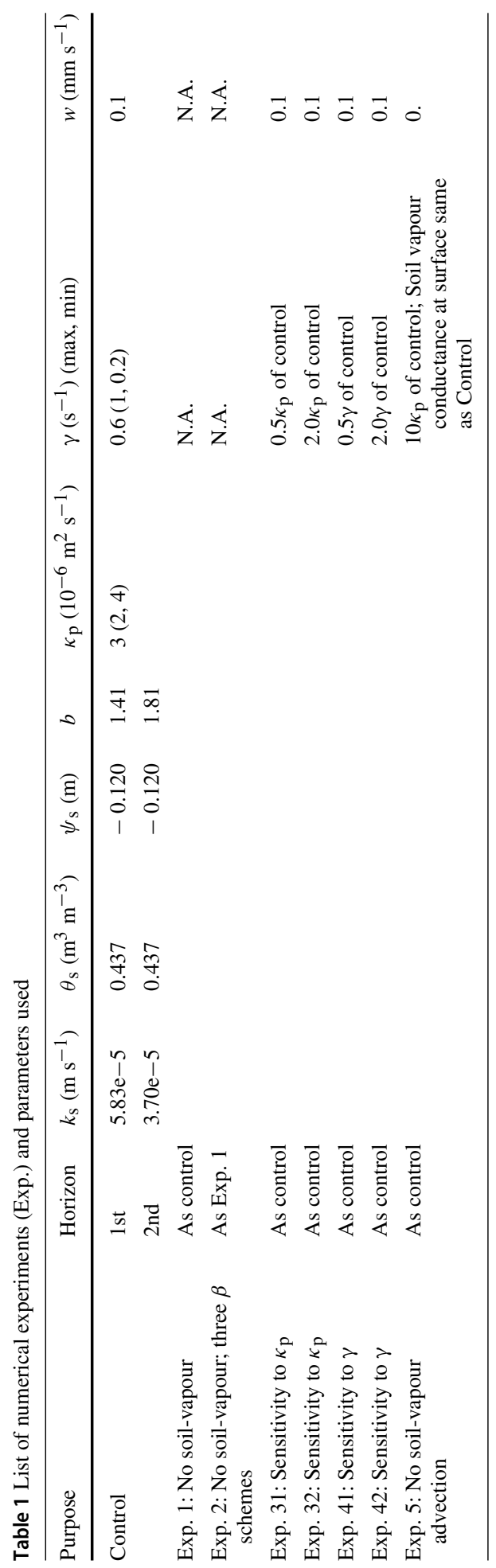



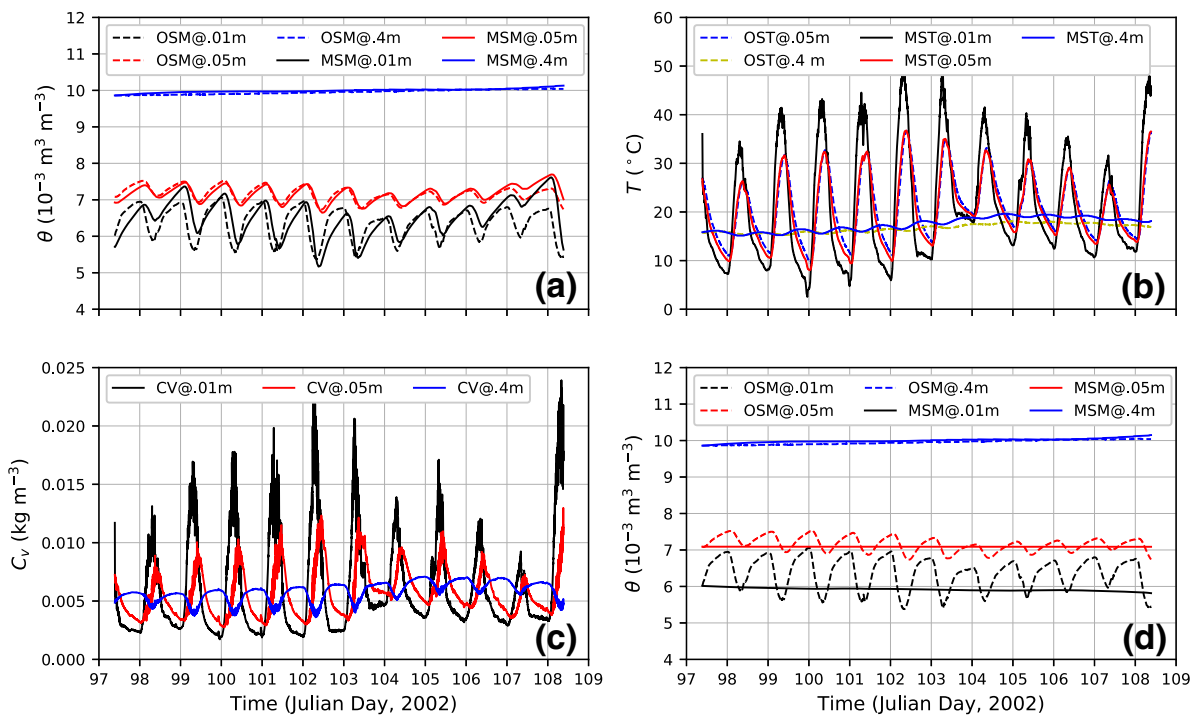

Fig. 4 a Simulated volumetric soil moisture $\theta\left(\mathrm{m}^{3} \mathrm{~m}^{-3}\right.$ ) at depths $0.01,0.05$, and $0.4 \mathrm{~m}$ (corresponding to model layers 1,3, and 6), labelled as MSM@.01 m,MSM@.05 m, and MSM@.4 m, respectively, compared with the observed soil moisture at the same depths, labelled as OSM@.01 m etc.; b As (a), but for soil temperature $T\left({ }^{\circ} \mathrm{C}\right)$ Measurements at $0.01 \mathrm{~m}$ are missing due to instrument failure; c Simulated soil-vapour concentration $C_{\mathrm{V}}\left(\mathrm{kg} \cdot \mathrm{m}^{-3}\right)$ at soil depths $0.01,0.05$, and $0.4 \mathrm{~m}$; d As (a), but for the simulation with no soil-vapour phase

The ALSIS-D simulated and observed soil moisture $\theta$ and soil temperature $T$ are presented in Fig. 4a and b, with the model reproducing the observations reasonably well both quantitatively and quantitatively. The value of $T$ undergoes diurnal variations with reduced amplitude and delayed phase as the soil depth increases, which is a well-known phenomenon resulting from the diurnal variation of radiation and soil heat conduction. The value of $\theta$ also varies diurnally with a reduced amplitude and delayed phase as the soil depth increases. Likewise, the soil-vapour concentration $C_{\mathrm{v}}$ shows a behaviour similar to the soil temperature. During the daytime, the value of $C_{\mathrm{v}}$, is much higher than that during night-time. The simulated soil moisture with no soil-vapour phase is presented in Fig. 4d, illustrating no diurnal variations, as at such a low soil moisture, hydraulic processes cease to play a significant role. A comparison of Fig. $4 a$, d reveals that, under extremely dry conditions, the evolution of soil moisture is governed by evaporation in the soil and the soil -vapour and air-vapour exchange.

Figure $5 \mathrm{a}$ and $\mathrm{b}$ presents scatter plots of the soil temperature $T$ versus the soil moisture $\theta$ for the first three model soil layers, and the soil-vapour concentration $C_{\mathrm{v}}$ versus $\theta$, respectively. Both the soil temperature $T$ and the soil moisture $\theta$ vary diurnally, oscillations, as already seen in Fig. 4a and b, but their oscillations are opposite in phase, i.e., as the soil temperature $T$ reaches maximum in the daytime, the value of $\theta$ is minimum, and as the value of $T$ reaches minimum at night-time, the value of $\theta$ is maximum. In contrast, the variables $T$ and $C_{\mathrm{v}}$ are in phase, and so it follows that $\theta$ and $C_{\mathrm{v}}$ are opposite in phase. The phase relationship between the variables $T, \theta$, and $C_{\mathrm{v}}$ reveals that the behaviour of $\theta$ and $C_{\mathrm{v}}$ is mainly governed by soil thermal processes.

Figure 6 further presents diurnal variations of the processes influencing soil moisture and soil vapour in the first soil layer, showing the first two terms on the right-hand side of (13), 

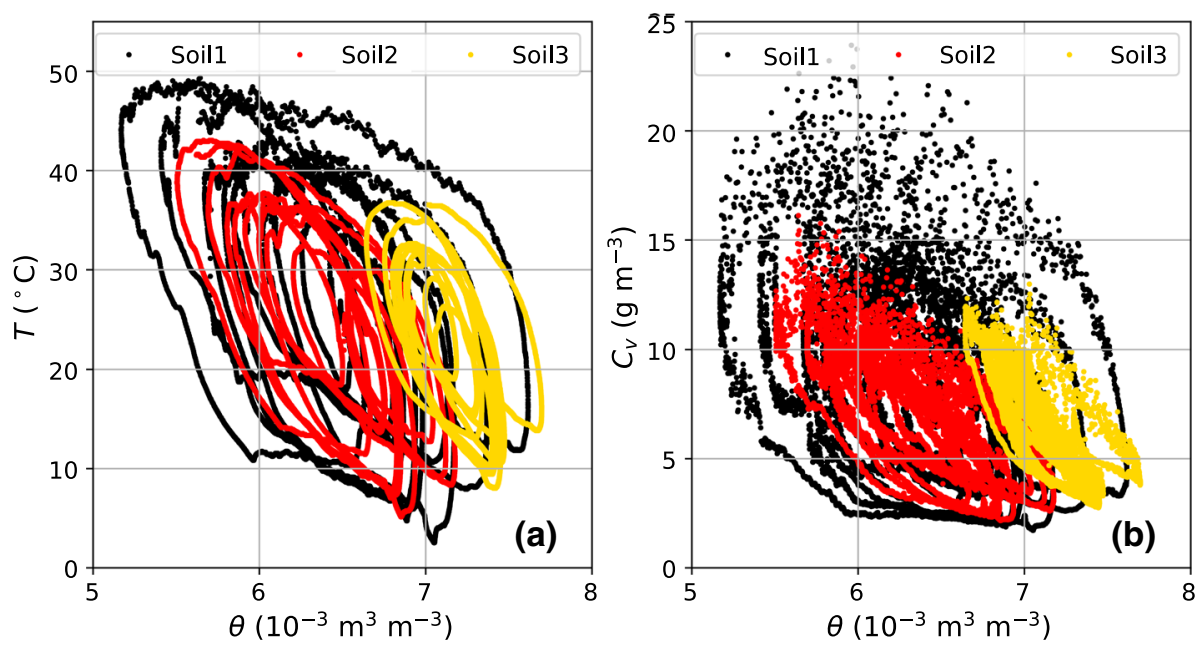

Fig. 5 Scatter plots of a soil temperature $T\left({ }^{\circ} \mathrm{C}\right)$ versus soil moisture $\theta\left(\mathrm{m}^{3} \mathrm{~m}^{-3}\right)$ for the first three soil layers, and $\mathbf{b}$ soil-vapour concentration $C_{\mathrm{V}}\left(\mathrm{g} \mathrm{m}^{-3}\right)$ versus $\theta$

namely, the terms $E_{\mathrm{w}}$ and $J_{\mathrm{w}} \equiv \rho_{\mathrm{w}} \frac{\partial}{\partial z} K\left(1-\frac{\partial \psi}{\partial z}\right)$ (for visualization $10 J_{\mathrm{w}}$ is plotted). In general, the term $J_{\mathrm{w}}$ is two orders of magnitude smaller than the term $E_{\mathrm{w}}$, because, under such dry conditions, the hydraulic fluxes are very small. The small variations in the value of $J_{\mathrm{w}}$ seen in Fig. 6 arise from evaporation (as described by Eq. 5) with $P_{\mathrm{r}}=0$ and $R_{\mathrm{f}}=0$, and the infiltration $I=-E$; for the first soil layer with depth $\mathrm{d} z_{1}, J_{\mathrm{w}} \approx-E / \mathrm{d} z_{1}$. Also plotted in Fig. 6 are normalized soil moisture and soil vapour (the normalization follows $x_{\mathrm{nm}}=$ $(x-\bar{x}) / 3 \sigma_{x}$, with $x$ being an arbitrary variable, $\bar{x}$ its mean, and $\sigma_{x}$ its standard deviation). Soil moisture shows a relatively short drying phase from early morning (0730 LT, local time $=\mathrm{UTC}+8 \mathrm{~h})$ to early afternoon (1430 LT) as the surface warms up and the value of $E_{\mathrm{w}}$ stays positive. During this period, soil moisture is converted to soil vapour, followed by a relatively longer wetting phase from early afternoon to early morning next day as the surface cools and the value of $E_{\mathrm{w}}$ stays negative. During this period, soil vapour is converted to soil moisture. As a consequence, soil moisture and soil vapour are almost opposite in phase, and soil vapour has a relatively short increasing phase and long decreasing phase.

\subsection{Impact on the Surface Energy Balance}

We ask whether the inclusion of the soil-vapour phase has significant influences on the surface energy balance (see Eq. 12). To this end, we compare the differences of the energy fluxes between the control and experiment 1 , model runs with and without the soil-vapour phase, respectively. The energy-flux difference is denoted as $\Delta$, e.g., $\Delta R_{\mathrm{n}}=R_{\mathrm{n}}$ (control) $R_{\mathrm{n}}$ (experiment 1$), \Delta H=H($ control) $-H$ (experiment 1$)$, etc. The integrals of $\Delta R_{\mathrm{n}}, \Delta H$, etc. over time are respectively denoted as $C R_{\mathrm{n}}, C H$, etc. The statistical parameters of the energy fluxes for the control and the energy-flux differences between the control and experiment 1 (Table 2) show that the impact of the soil-vapour phase on the surface energy balance is small, especially on net radiation and latent heat flux. The small $\Delta R_{\mathrm{n}}$ values originate from the differences in surface soil temperature, on which the soil-vapour phase does have a noticeable influence. The soil-vapour phase has a slightly more obvious influence on sensible heat and 


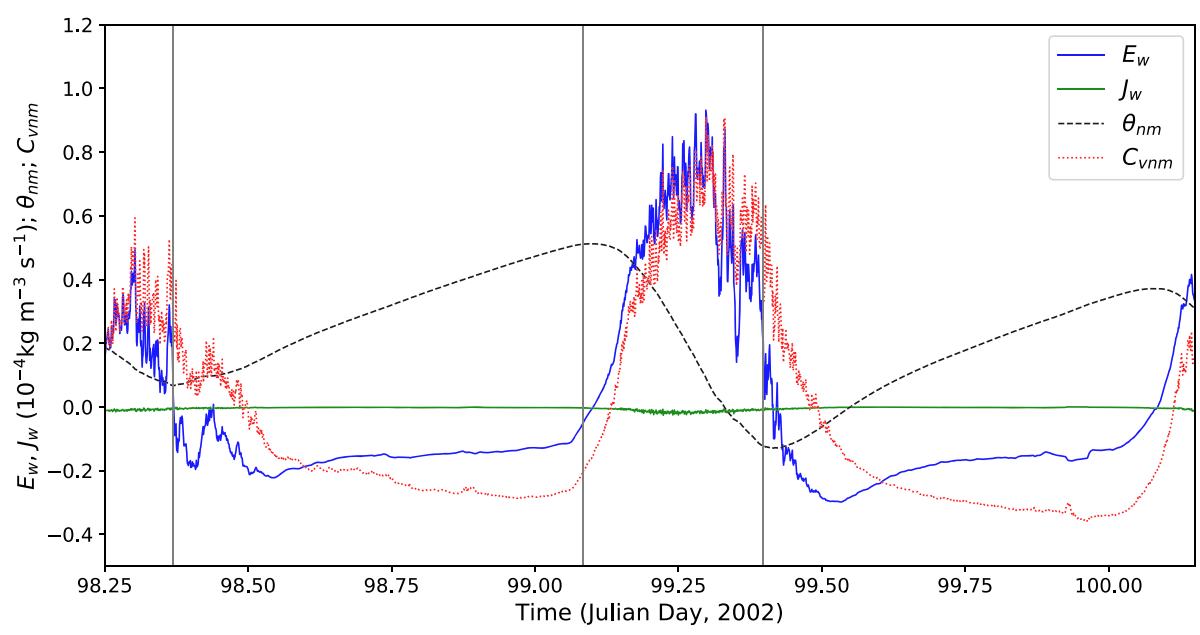

Fig. 6 A section of the time series of soil-moisture sources $E_{\mathrm{W}}$ and $J_{\mathrm{W}}$ for the first soil layer. The normalized soil moisture, $\theta_{\mathrm{nm}}$, and normalized soil-vapour concentration, $C_{\mathrm{vnm}}$, are also plotted. The soil moisture drying and wetting phases are marked

ground heat fluxes. This is because the vapour exchange between the soil and atmosphere does not involve latent heat but the exchange between soil moisture and soil vapour does, which then influences soil temperature and surface sensible-heat and ground-heat fluxes.

Figure $7 \mathrm{a}, \mathrm{b}$ presents the variables $R_{\mathrm{n}}, H, L E$, and $G$ for the control experiment and the variables $\Delta R_{\mathrm{n}}, \Delta H, \Delta L E$, and $\Delta G$ to show the diurnal variations of the energy fluxes and the impact of the soil-vapour phase on the energy fluxes. Figure 7c presents the variables $C R_{\mathrm{n}}$, $C H, C L E$, and $C G$ for the complete observational period. Figure 7 a reveals that the surface energy balance is typical for an arid land surface, for which the latent heat flux is negligibly small and the energy balance is mainly achieved between the net radiation, sensible heat, and ground heat fluxes. Figure $7 \mathrm{~b}$ shows that $\Delta R_{\mathrm{n}}$ is mostly weakly negative, but fluctuates over several $\mathrm{W} \mathrm{m}^{-2}$ (in this example $\pm 4 \mathrm{~W} \mathrm{~m}^{-2}$ ) during the daytime. The value of $\Delta H$ is mostly weakly positive but fluctuates (in this example) between 5 and $-15 \mathrm{~W} \mathrm{~m}^{-2}$ during the daytime, while $\Delta G$ attains almost the same magnitude (but of opposite sign) as $\Delta H$. Figure 7c shows that $C R_{\mathrm{n}}$ over the study period accumulates to about $-100 \mathrm{~kJ} \mathrm{~m}^{-2}, \mathrm{CH}$ about $200 \mathrm{~kJ} \mathrm{~m}^{-2}$, and $C G$ about $-300 \mathrm{~kJ} \mathrm{~m}^{-2}$. The variation in the quantities $C R_{\mathrm{n}}, C H$, and $C G$ indicate both diurnal and synoptic scale variations.

\section{Discussion}

The quantitative modelling of soil moisture and land-surface processes under extremely dry conditions can be affected by a number of parameters and are associated with uncertainties. We first ask whether it is possible to tune the conventional evaporation scheme to achieve the observed soil-moisture variations at the Qira site, without invoking the soil-vapour phase. To this end, we run the ALSIS model (no soil-vapour phase) with three different $\beta$ functions, namely, (8, 26), and (27)

$$
\beta=0.25\left[1-\cos \left(\pi\left(\theta_{1} / \theta_{s}\right)^{2}\right)\right],
$$



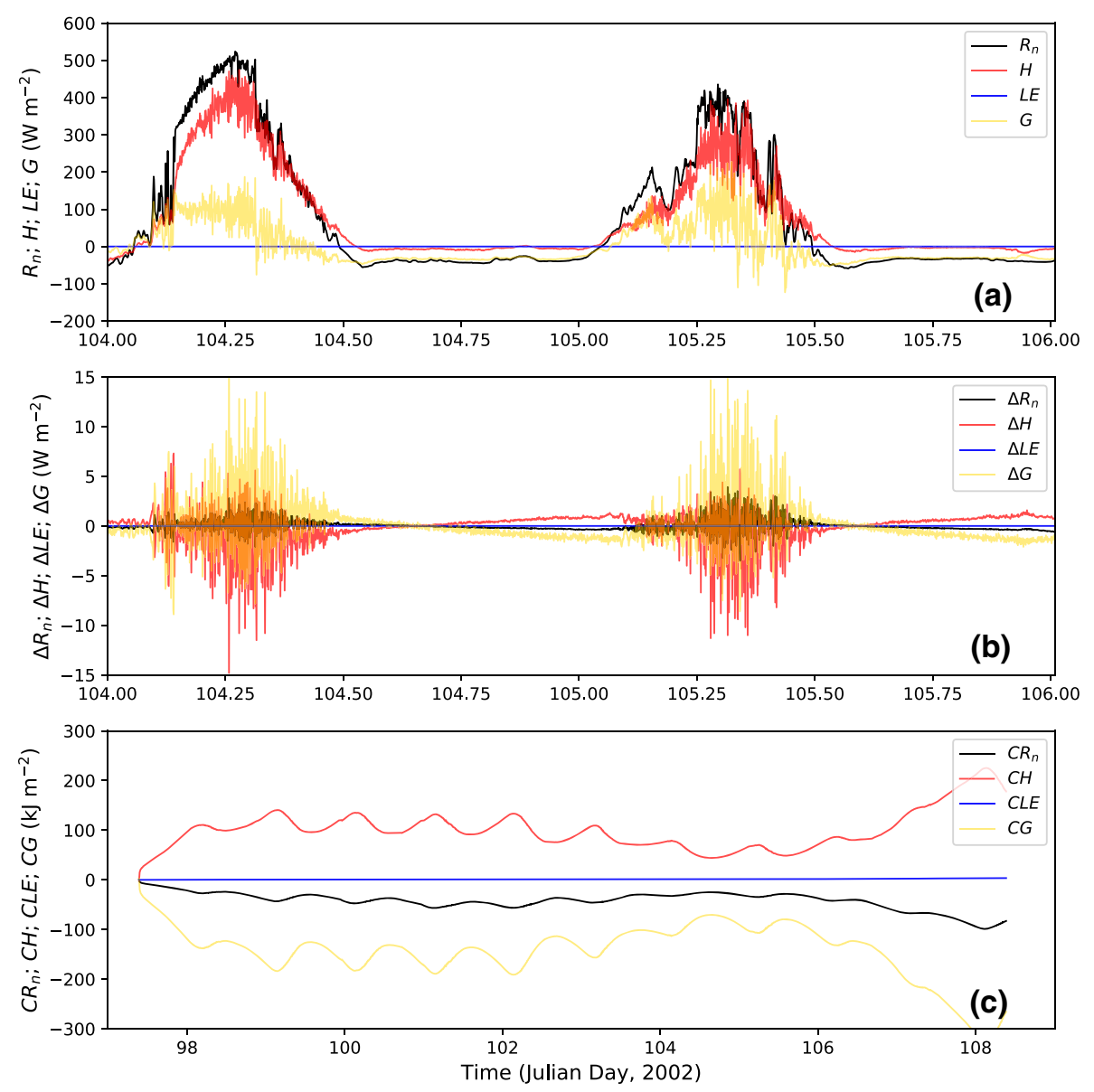

Fig. 7 Time series of parameters a $R_{\mathrm{n}}, H, L E$, and $G$ showing their diurnal variations, $\mathbf{b} \Delta R_{\mathrm{n}}, \Delta H, \Delta L E$, and $\triangle G$, and $\mathbf{c} C R_{\mathrm{n}}, C H, C L E$, and $C G$

$$
\beta=0.50\left[1-\cos \left(\pi\left(\theta_{1} / \theta_{s}\right)^{1}\right)\right]
$$

Model simulations show that only varying $\beta$ cannot reproduce the observed soil-moisture variations (not shown). With increased evaporation (e.g., by using Eq. 27), soil moisture in the top soil layer continues to dry out to zero, and soil moisture in deeper soil layers does not change with time (similar to Fig. 4d). We conclude that, without the soil-vapour phase, the model cannot reproduce the observed behaviour of soil moisture.

Additional runs (see Table 1) are made to test the model sensitivity to the parameters $\gamma$ in (20), and $\kappa_{\mathrm{p}}$ and $w$ in (14). In experiment 31 and 32, the value of $\kappa_{\mathrm{p}}$ of the control experiment is, respectively, decreased and increased by a factor of two. Figure 8 shows that an increased value of $\kappa_{\mathrm{p}}$ leads to an increased soil moisture and its (amplitude of) diurnal variation due to the increased soil-vapour exchange with the atmosphere and diffusion within the soil column. As the value of $\kappa_{\mathrm{p}}$ increases, the modelled soil moisture agrees better with the observations, but a noticeable phase delay persists. 


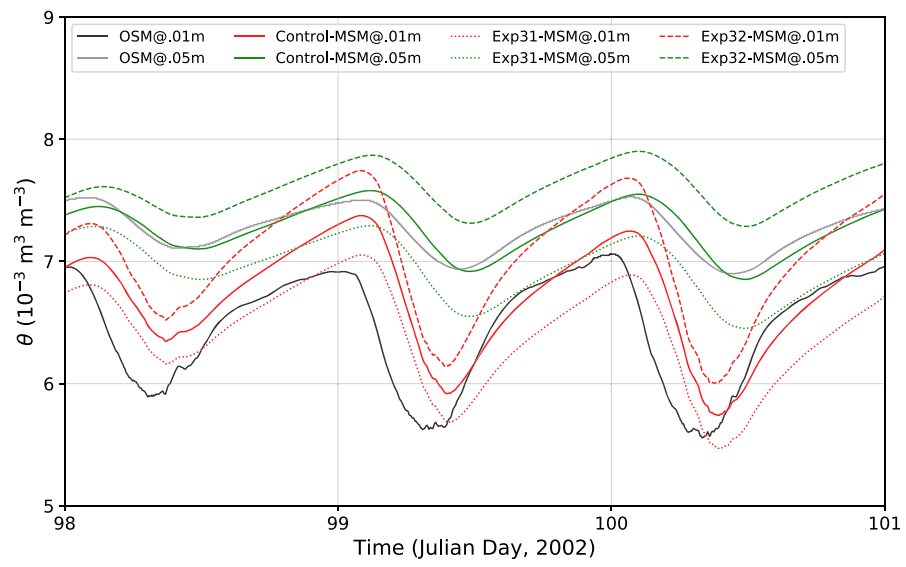

Fig. 8 A section of observed and ALSIS-D simulated soil moisture at 0.01-m and 0.05-m soil depths with $\kappa_{\mathrm{p}}$ $=3 \times 10^{-6} \mathrm{~m}^{2} \mathrm{~s}^{-1}$ (Control), $1.5 \times 10^{-6} \mathrm{~m}^{2} \mathrm{~s}^{-1}$ [experiment (Exp.) 31] and $6 \times 10^{-6} \mathrm{~m}^{2} \mathrm{~s}^{-1}$ (Exp. 32)

Table 2 Statistics of the surface energy fluxes for the control and the surface-energy-flux differences between the control and experiment 1

The abbreviations Std, Max, and Min stand for standard deviation, maximum, and minimum, respectively

\begin{tabular}{lllll}
\hline Variable & $\begin{array}{l}\text { Mean } \\
\left(\mathrm{W} \mathrm{m}^{-2}\right)\end{array}$ & $\begin{array}{l}\mathrm{Std} \\
\left(\mathrm{W} \mathrm{m}^{-2}\right)\end{array}$ & $\begin{array}{l}\text { Max } \\
\left(\mathrm{W} \mathrm{m}^{-2}\right)\end{array}$ & $\begin{array}{l}\text { Min } \\
\left(\mathrm{W} \mathrm{m}^{-2}\right)\end{array}$ \\
\hline$R_{\mathrm{n}}$ & 76 & 185 & 552 & -125 \\
$H$ & 70 & 132 & 600 & -86 \\
$L E$ & 0.01 & 0.01 & 0.05 & 0.00 \\
$G$ & 6 & 69 & 320 & -418 \\
$\Delta R_{\mathrm{n}}$ & -0.1 & 0.7 & 8.0 & -9.2 \\
$\Delta H$ & 0.2 & 2.2 & 36.8 & -32.4 \\
$\Delta L E$ & 0.003 & 0.006 & 0.039 & -0.026 \\
$\Delta G$ & -0.3 & 2.9 & 40.5 & -45.8 \\
\hline
\end{tabular}

In experiments 41 and 42 , the value of $\gamma$ of the control experiment is, respectively, reduced and increased by a factor of two. Figure 9 shows that as the value of $\gamma$ increases, soil moisture decreases and the amplitude of its diurnal variation increases. This is understandable, because a larger $\gamma$ value implies faster conversion between the soil-moisture and soil-vapour phases. It is also seen that an increased value of $\gamma$ results in larger phase delays in the modelled soil moisture.

In experiment 5, the value of $w$ in (14) is set to zero (no soil-vapour advection in soil), but $\kappa_{\mathrm{p}}$ is increased by a factor of 10 to achieve reasonable model-observation agreement in the top-layer soil moisture. Figure 10 presents the normalized observed and modelled soil moisture for soil layer 3, showing that, while the observed and control-simulated soil moisture are in reasonable phase agreement, albeit with a delay in the latter, the observed and experiment-5-simulated soil moisture are almost opposite in phase. Various other tests by varying other relevant parameters, such as $\kappa_{\mathrm{p}}$ and $\gamma$, but with the soil-vapour advection term in (14) switched off, do not give better results, suggesting that soil-vapour advection plays a role in the soil-moisture evolution.

The ALSIS-D simulations show that the soil-vapour exchange with the atmosphere is responsible for the observed variations of soil moisture under extremely dry conditions. However, as can be seen in Figs. 8, 9 and 10, the modelled soil moisture has a noticeable 


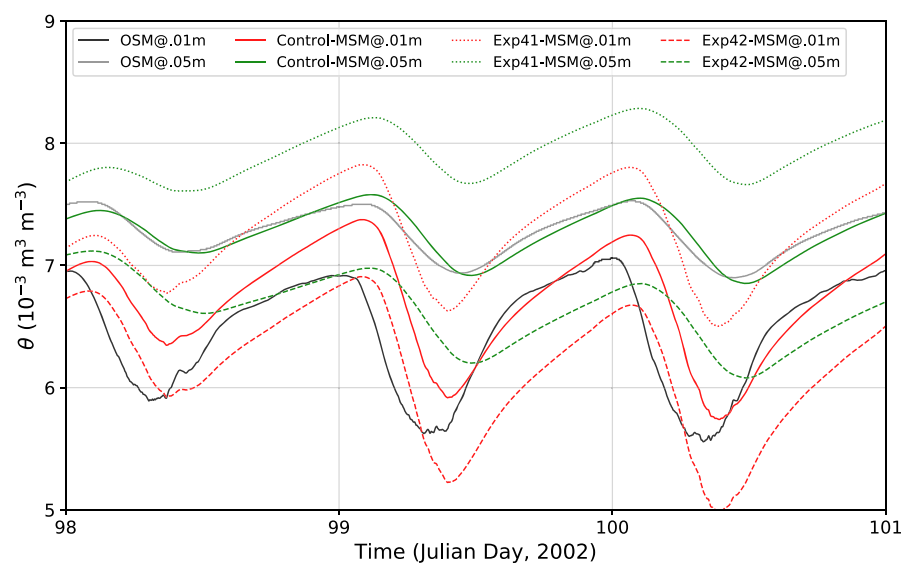

Fig. 9 As Fig. 8, but simulated soil moisture for soil layers 1 and 3 with $\gamma=0.6 \mathrm{~s}^{-1}$ (control), $0.3 \mathrm{~s}^{-1}$ [experiment (Exp.) 41] and $1.2 \mathrm{~s}^{-1}$ (Exp. 42)

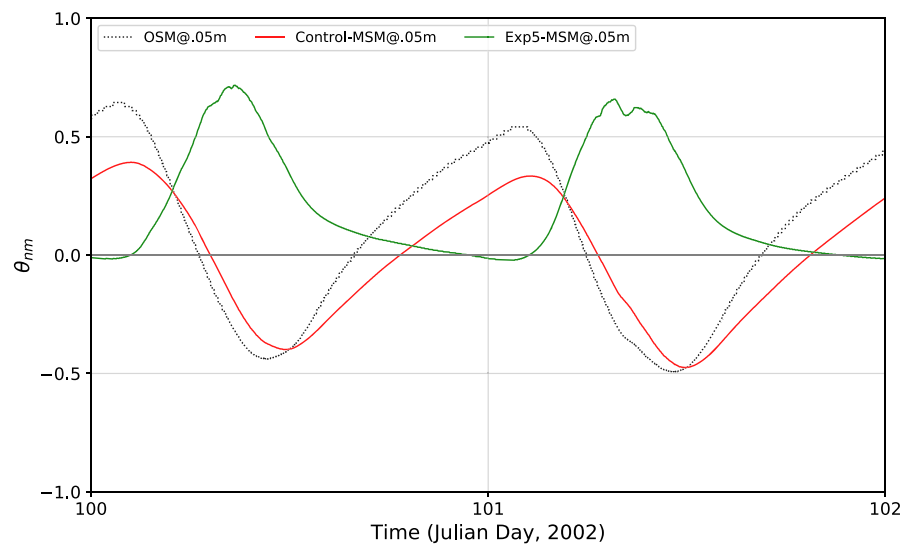

Fig. 10 Normalized observed soil moisture at 0.05 m (OSM@.05 m) and normalized modelled soil moisture at the same soil depth for the control (Control-MSM@.05 m) and experiment 5 (Exp5-MSM@.05 m)

delay in the phase in comparison with the observations. Tuning of the newly introduced parameters does not alleviate this deficiency. The most likely reason for the persisted phase delay is that we have assumed in the model that internal soil evaporation is related to the soil temperature, which has a phase delay in comparison to the temperature of the air. It may be that the air temperature in soil differs from the soil temperature, and it is the former temperature which influences the internal soil evaporation. Here, the temperature of the air in soil is not simulated.

\section{Conclusions}

In a hyper-arid environment, soil moisture in the top soil layer of depth 0.01 to $0.1 \mathrm{~m}$, although very low, continues to show clear temporal variations, as observed by Ishizuka et al. (2005a) in the Taklamakan Desert. Existing land-surface schemes, in which soil-hydraulic processes 
are assumed to determine the behaviour of soil moisture, cannot model such variations. We have shown that soil-moisture variations in hyper-arid conditions occur due to internal soil evaporation and vapour fluxes at the air-soil interface. Conceptually, the unsaturated soil zone can be further divided into two subzones. In subzone II, the evolution of soil moisture is governed by Darcy flow, and in subzone I, by evaporation and condensation in soil pores. To better model land-surface processes in arid regions, the air-soil vapour exchange needs to be considered.

We included the air-soil vapour exchange in the ALSIS-D model (revised version based on the ALSIS model, Irannejad and Shao 1998; Shao and Irannejad 1999). The main problem for inclusion of the soil-vapour phase in LSMs is to quantify the soil-moisture and soil-vapour exchange, namely, $E_{\mathrm{w}}$, the evaporation rate per unit soil volume, which is computed here using Eq. 21. The new parameter $\gamma$, which is relatively unknown, is of $O(1)$ and is expected to depend on soil pore characteristics. Using the ALSIS-D model, we simulated soil moisture at the Qira site and compared the model results with the observations. The following conclusions are made.

1. The ALSIS-D model can reasonably well reproduce the observed soil-moisture behaviour at the Qira site, which confirms our hypothesis, and shows that soil-moisture evolution in hyper-arid conditions is primarily influenced by the soil-vapour phase.

2. The diurnal variation of soil moisture in hyper-arid conditions is closely related to soil temperature. Soil moisture shows a relatively short drying phase from early morning to early afternoon as the surface warms. During this time, $E_{\mathrm{w}}$ is positive and soil moisture is converted to soil vapour, followed by a longer wetting phase from the early afternoon to the early morning next day as the surface cools. During this time, $E_{\mathrm{w}}$ is negative and soil vapour is converted to soil moisture. Consequently, soil moisture and soil vapour are opposite in phase, while soil temperature and soil vapour are similar in phase.

3. The influence of the soil-vapour phase on the surface energy balance is not excessive, but nevertheless measurable. Due to the inclusion of the soil-vapour phase, the value of $\Delta R_{\mathrm{n}}$ is on average weakly negative but fluctuates over several $\mathrm{W} \mathrm{m}^{-2}$ during the daytime; $\Delta H$ is weakly positive but fluctuates in the range of -15 to $5 \mathrm{~W} \mathrm{~m}^{-2}$ during daytime; $\Delta G$ is weakly negative and balances the term $\Delta\left(R_{\mathrm{n}}-H\right)$. There is little influence on the latent heat flux $L E$, as the air-soil vapour exchange does not contribute to the latent heat flux. Over the Qira observational period (12 days), the cumulative net radiation, $C R_{\mathrm{n}}$, sensible heat, $C H$, and ground heat, $C G$, amount to $-100 \mathrm{~kJ} \mathrm{~m}^{-2}, 200 \mathrm{~kJ} \mathrm{~m}^{-2}$ and $-300 \mathrm{~kJ} \mathrm{~m}^{-2}$, respectively.

4. To achieve a good agreement with the observed soil moisture at all three depths, it is found that a soil-vapour-advection process needs to be included in the ALSIS-D model, as otherwise, simulated and observed soil moisture are almost opposite in phase already at the $0.05-\mathrm{m}$ soil depth. This suggests that soil-vapour advection may be occurring in the soil column, at least at the Qira Gobi site. It is not clear whether this is due to the special characteristics of the soil column at the field site (e.g., large pores due to the presence of rocks) or other processes which play an important role in general.

The ALSIS-D simulated soil moisture and observed soil moisture can agree well in magnitude, but the simulated soil moisture is somewhat delayed in phase. By simple tuning of the existing model parameters, we cannot alleviate this model deficiency, suggesting that other physical processes or nonlinear dependencies still need to be considered to fully explain the discrepancy. It is likely that internal soil evaporation depends on the air temperature in soil, which differs from the soil temperature. This consideration is yet to be tested. 
In the study period, the soil temperature was above the freezing point and the soil was not frozen. But in the Taklamakan Desert in winter, soil can be frozen. In this case, the basic concept presented here would remain valid, but some modifications would be necessary, such as the inclusion of sublimation and adjustment to Eq. 21. Because we have no frozen soil observation, this case is not investigated. The Taklamakan, as many other deserts on earth, is subject to frequent dust activities. Soil moisture is a key factor influencing the threshold friction velocity for aeolian activities. The modelling of soil moisture in extremely dry conditions, as shown here, is particularly relevant for aeolian research.

Acknowledgements This research is funded by the Deutsche Forschungsgemeinschaft (DFG)—Project Number 268236062 - SFB 1211.

Funding Open Access funding enabled and organized by Projekt DEAL.

Open Access This article is licensed under a Creative Commons Attribution 4.0 International License, which permits use, sharing, adaptation, distribution and reproduction in any medium or format, as long as you give appropriate credit to the original author(s) and the source, provide a link to the Creative Commons licence, and indicate if changes were made. The images or other third party material in this article are included in the article's Creative Commons licence, unless indicated otherwise in a credit line to the material. If material is not included in the article's Creative Commons licence and your intended use is not permitted by statutory regulation or exceeds the permitted use, you will need to obtain permission directly from the copyright holder. To view a copy of this licence, visit http://creativecommons.org/licenses/by/4.0/.

\section{References}

Blender R, Fraedrich K (2006) Long term memory of the hydrological cycle and river runoffs in China in a high-resolution climate model. Int J Climatol 26:1547-1565

Brooks RH, Corey AT (1964) Hydraulic properties of porous media. Hydroloy Paper 3, Colorado State University, Fort Collins

Chen F, Dudhia J (2001) Coupling an advanced land surface-hydrology model with the Penn State-NCAR MM5 modeling system. Part I: model implementation and sensitivity. Mon Weather Rev 129:569-585

Clapp RB, Hornberger GM (1978) Empirical equations for some soil hydraulic properties. Water Resour Res 14:601-604

Irannejad P, Shao Y (1998) Description and validation of the atmosphere-land-surface interaction scheme (ALSIS) with HAPEX and Cabauw data. Glob Planet Change 19:87-114

Ishizuka M, Mikami M (2005) Measurement of soil water content in a hyper-arid environment using timedomain reflectometry sensors. Hydrol Proc 19:3911-3920

Ishizuka M, Mikami M, Yamada Y, Zeng FJ, Gao W (2005a) An observational study of soil moisture effects on wind erosion at a gobi site in the Taklimakan Desert. J Geophys Res 110:D18S03. https://doi.org/10. 1029/2004JD004709

Ishizuka M, Mikami M, Zeng FJ, Gao W, Yamada Y (2005b) Measurements of soil water content using time domain reflectometry sensor and water vapor in the surface soil layer at the gobi site in the Taklimakan Desert. J Meteorol Soc Jpn 83:987-999

Kondo J, Saigusa N, Sato T (1990) Parameterization of evaporation from bare soil surfaces. J Appl Meteorol 29:385-389

Lee J, Pielke RA (1992) Estimating the soil surface specific humidity. J Appl Meteorol 31:480-484

Li JM, Wang CH (2020) An evaporation correction approach and its characteristics. J Hydrometeorol 21:519-532

Mahfouf JF, Noilhan J (1991) Comparative study of various formulations of evaporation from bare soil using in situ data. J Appl Meteorol 30:1354-1365

McKenna Neuman C, Sanderson S (2008) Humidity control of particle emissions in aeolian systems. J Geophys Res 113:F02S14. https://doi.org/10.1029/2007JF000780

Mikami M, Osamu A, Du MY, Chiba O, Fujita K, Hayashi M, Iwasaka Y, Kai K, Masuda K, Nagai T, Ootomo T, Suzuki J, Uchiyama A, Yabuki S, Yamada Y, Yasui M, Shi GY, Zhang XY, Shen ZB, Wei WS, Zhou J (2002) The impact of aeolian dust on climate: sino-Japanese Cooperative Project ADEC. J Arid Land Studies 11:211-222 
Mikami M, Te Aoki, Ishizuka M, Yabuki S, Yamada Y, Gao W, Zeng FJ (2005) Observation of number size distribution of desert aerosols in the south of the Taklimakan Desert, China. J Meteorol Soc Jpn 83A:31-43

Oleson KW, Lawrence DM et al. (2013) Technical Description of version 4.5 of the Community Land Model (CLM). NCAR/TN-503 + STR NCAR Technical Note, ISSN 2153-2397

Shao Y, Irannejad P (1999) On the choice of soil hydraulic models in land-surface schemes. Boundary-Layer Meteorol 90:83-115

Shao Y, Mikami M (2005) Heterogeneous saltation: theory, observation and comparison. Boundary-Layer Meteorol 115:359-379

van Genuchten MTh (1980) A closed-form equation for predicting the hydraulic conductivity of unsaturated soils. Soil Sci Soc Am J 44:892-898

Wang G, Dolman AJ, Blender R, Fraedrich K (2010) Fluctuation regimes of soil moisture in ERA-40 rereanalysis data. Theor Appl Climatol 99:1-8

Publisher's Note Springer Nature remains neutral with regard to jurisdictional claims in published maps and institutional affiliations. 